\title{
sciendo
}

\section{THE EFFECT OF ADDING HERBAL EXTRACTS TO DRINKING WATER ON BODY TEMPERATURE, LEVEL OF THYROID HORMONES AND H:L RATIO IN THE BLOOD OF BROILER CHICKENS EXPOSED TO ELEVATED AMBIENT TEMPERATURE*}

\author{
Iwona Skomorucha ${ }^{1 \star}$, Ewa Sosnówka-Czajka² \\ Department of Poultry Breeding, National Research Institute of Animal Production, \\ 32-083 Balice n. Kraków, Poland \\ •Corresponding author: iwona.skomorucha@iz.edu.pl \\ Orcid number: \\ ${ }^{1} 0000-0003-1241-7703$ \\ ${ }^{2} 0000-0003-3720-1685$
}

\begin{abstract}
The aim of the study was to determine the effect of supplementing drinking water with extracts from lemon balm, sage and nettle on body temperature, level of thyroid hormones and the heterophil to lymphocyte (H:L) ratio in the blood of broiler chickens exposed to elevated rearing temperature. One-day-old Ross 308 chicks were divided into four groups: group I (CON) and experimental groups II (LB), III (S) and IV (N), in which, from 22 to 42 days of rearing, drinkers were supplemented with lemon balm extract, sage extract or nettle extract $(2 \mathrm{ml} / \mathrm{l}$ water $)$, respectively. In addition, at 5 weeks of growth, all the groups were exposed to elevated ambient temperature (up to $30^{\circ} \mathrm{C}$ ) for 5 days, after which the recommended thermal conditions were reinstated. During the study, mortality, rectal temperature and radiated temperature of the broilers were monitored. Blood was collected from $\mathbf{1 0}$ birds per group to determine the concentration of thyroid hormones $\left(T_{3}\right.$ and $\left.T_{4}\right)$ and to make blood smears. The $H: L$ ratio was determined based on the percentage of heterophils $(\mathrm{H})$ and lymphocytes $(\mathrm{L})$. The herbal extracts from lemon balm, sage and nettle, added to drinking water at $2 \mathrm{ml} / \mathrm{l}$, reduced the blood level of the thyroid hormone (triiodothyronine) and rectal temperature in the experimental broilers during the initial period of thermal stress. Chickens receiving the nettle extract were also characterised by lower radiated temperature of the unfeathered body, a lower $\mathrm{H}: \mathrm{L}$ ratio in the blood during the increase in ambient temperature, and the lowest mortality percentage. It can therefore be considered that the dietary supplementation of nettle, in the form and concentration used in this study, had the most favourable effect on the physiological status of the birds (body temperature, level of thyroid hormones and $\mathrm{H}: \mathrm{L}$ ratio) exposed to elevated ambient temperatures $\left(30^{\circ} \mathrm{C}\right)$, and thus on their welfare.
\end{abstract}

Key words: herbal extracts, elevated ambient temperature, physiological indicators, broiler chickens

\footnotetext{
*Work financed from statutory activity, project no. 06-009.1.
} 
High ambient temperature is a major stressor for farm animals (Attia and Hassan, 2017; Abd El-Hack et al., 2020). Modern lines of broiler chickens are particularly sensitive to high air temperatures (Song et al., 2018; Attia et al., 2018 a; Cheng et al., 2019) because their rapid growth, high body weight and good feed conversion increase the amount of heat energy they produce (Giloh et al., 2012; Lara and Rostagno, 2013; Wang et al., 2020), which inhibits the body's adaptation to adverse thermal conditions (Attia et al., 2017 a). The thermal comfort zone for homeothermic animals is characterised by a range of environmental temperatures, within which animals have minimal and nearly constant energy expenditure for maintaining body temperature (Cândido et al., 2020). According to Olanrewaju et al. (2010), the body temperature of an adult chicken is 40.6 to $41.7^{\circ} \mathrm{C}$, and the thermoneutral zone that allows chickens to maintain their body temperature is 18 to $24^{\circ} \mathrm{C}$. When birds are exposed to temperatures above their thermoneutral zone, heat exchange between the bird and its environment is impeded, which is reflected in altered physiological and metabolic reactions such as: endocrine disruption (Jiang et al., 2020), electrolyte imbalance (Attia et al., 2011), elevated body temperature (Giloh et al., 2012; Skomorucha and Sosnówka-Czajka, 2017; Vermette et al., 2017), increased heterophil to lymphocyte ratio (Vermette et al., 2017), immunosuppression (Xu et al., 2018), oxidative stress (Song et al., 2018), behavioural changes (Olanrewaju et al., 2010; Lara and Rostagno, 2013) and compromised productivity and meat quality (Olanrewaju et al., 2010; Saeed et al., 2019). According to many authors, high ambient temperatures cause substantial economic losses due to reduced weight gains and increased mortality of the birds (Wang et al., 2018; Saeed et al., 2019; Jiang et al., 2020).

An important role in thermoregulation and nutrient metabolism is played by the thyroid hormones thyroxine $\left(\mathrm{T}_{4}\right)$ and triiodothyronine $\left(\mathrm{T}_{3}\right)$, the level of which is associated among others with ambient temperature (Giloh et al., 2012; Jiang et al., 2020). Regulation of the concentration of $\mathrm{T}_{3}$ and $\mathrm{T}_{4}$ in the body is essential for maintenance of body temperature via energy metabolism in homeothermic animals (Jiang et al., 2020). In general, birds exposed to elevated ambient temperatures were reported to show reduced blood $\mathrm{T}_{3}$ levels (Sohail et al., 2010; Giloh et al., 2012; Mack et al., 2013; Skomorucha and Sosnówka-Czajka, 2017), and decreased (Sohail et al., 2010), increased (Giloh et al., 2012; Skomorucha and Sosnówka-Czajka, 2017) or unchanged $\mathrm{T}_{4}$ levels (Mack et al., 2013).

The current ongoing global warming generates increasing losses in the poultry industry due to hyperthermia in broiler chickens. There is therefore a need for finding practical methods to alleviate the negative impacts of heat stress in birds. Many authors have reported positive effects of the dietary inclusion of vitamins, minerals, amino acids, prebiotics and probiotics on heat-stressed poultry (Kumar et al., 2017; Cheng et al., 2019). Increasing interest is devoted to all kinds of plant-derived preparations (phytobiotics), which are easily available, cheap, safe for use, and contain antioxidants that regulate the metabolism and performance of birds exposed to heat stress (Abd El-Hack et al., 2020). Attia and Al-Harthi (2015) and El-Shoukary et al. (2014) observed that supplementing 1\% Nigella sativa seeds to the diets of broiler chickens exposed to elevated ambient temperatures, increased their daily weight gains, considerably reduced the number of panting birds, and decreased the 
corticosterone and $\mathrm{T}_{3}$ levels compared to the control group. In turn, Rehman et al. (2018) showed the dietary inclusion of $2 \%$ ginger led to considerable improvements in blood parameters and body weight gains of broiler chickens exposed to heat stress. The beneficial effects of herbal supplements on the body of broiler chickens reared under high ambient temperature were also reported by Ragab et al. (2013), Attia et al. (2017 b; 2018 b), Sadeghi and Moghaddam (2018), and Song et al. (2018).

Common and highly valued herbs include lemon balm, sage and nettle, which show various health-promoting benefits, and thanks to the presence of essential oils they have sedative and anti-stress effects. Furthermore, these plants show strong antioxidant properties (Poulios et al., 2020; Bonetti et al., 2016; Kasapidou et al., 2014), which makes them useful for reducing stress induced by high air temperature. However, the literature reports no information concerning the use of these herbs to alleviate the effects of heat stress on the avian body.

Therefore, the aim of the present study was to determine the effect of adding lemon balm, sage and nettle extracts to drinking water on the body temperature, level of thyroid hormones, and the heterophil to lymphocyte ratio $(\mathrm{H}: \mathrm{L})$ in the blood of broiler chickens exposed to high ambient temperature.

\section{Material and methods}

\section{Experimental site}

The experiment was conducted at a poultry farm of the National Research Institute of Animal Production in Aleksandrowice.

\section{Birds and experimental design}

The experimental material consisted of 640 day-old Ross 308 broiler chicks from the Poultry Hatchery in Łężkowice. At one day of age, the chicks were weighed, identified with tags and assigned to four groups (160 birds per group), each having four subgroups (40 birds per subgroups). Group I was the control (CON), and in groups II (LB), III (S) and IV (N) water drinkers were supplemented from 22 to 42 days of age with liquid alcoholic extract from lemon balm (Melissa officinalis L.), sage (Salvia officinalis L.) and nettle (Urtica dioica L.), respectively, at $2 \mathrm{ml} / 1$ water (Skomorucha and Sosnówka-Czajka, 2013). The experimental herbs were chosen mainly for their content of antioxidant substances (essential oils, flavonoids, polyphenolic acids, $\beta$-carotenoids, chlorophyll ( $\mathrm{a}$ and $\mathrm{b}$ ), xanthophylls and vitamins $\mathrm{C}$ and E). Additionally, birds in all the four groups were exposed to high ambient temperature $\left(30^{\circ} \mathrm{C}\right)$ from 30 to 35 days of age and normal thermal conditions $\left(20-18^{\circ} \mathrm{C}\right)$ from 36 to 42 days of age. The birds were raised for 42 days on litter at a stocking density less than $33 \mathrm{~kg} / \mathrm{m}^{2}$ (Regulation of the Minister of Agriculture and Rural Development, Journal of Laws 2010 no. 56 item 344). The lighting schedule was 23L:1D for the first 7 days, and then 20L:4D from 8 to 38 days and 23L:1D from 39 to 42 days. The chickens were fed ad libitum starter (up to week 3), grower (weeks 4 to 5) and finisher diets (week 6) based on concentrates (Table 1). Feed was fed from feed hop- 
pers. Drinking water supplemented with herbal extract was provided in bell drinkers. The water were manually replenished twice a day. Throughout rearing, the broilers had free access to the feed and water drinkers.

Ethanol herb extracts were produced by a professional herbal company and were certified to conform with in-house quality standard (ZN-16/NX/900, ZN-07/ $\mathrm{NX} / 523, \mathrm{ZN}-11 / \mathrm{NX} / 546$ ).

The experiment was approved by the Second Local Ethics Committee for Animal Experiments in Kraków (no. 1205/2015).

Table 1. Ingredient composition (\%) and nutritive value of the diets

\begin{tabular}{|c|c|c|}
\hline \multirow[b]{2}{*}{ Item } & \multicolumn{2}{|c|}{ Diet } \\
\hline & $\begin{array}{c}\text { Starter }^{1} \\
1-21 \text { days }\end{array}$ & $\begin{array}{c}\text { Grower }^{2} \text {, Finisher } \\
22-42 \text { days }\end{array}$ \\
\hline Maize & 55.35 & 47.21 \\
\hline Soybean meal & 37.5 & 33.75 \\
\hline Wheat & - & 10.00 \\
\hline Rapeseed oil & 2.90 & 4.80 \\
\hline Ground limestone & 1.10 & 1.15 \\
\hline Dicalcium phosphate & 2.10 & 2.00 \\
\hline Sodium chloride & 0.30 & 0.30 \\
\hline Vitamin-mineral premix & 0.50 & 0.50 \\
\hline L-Lysine & 0.03 & 0.09 \\
\hline DL-Methionine & 0.22 & 0.20 \\
\hline \multicolumn{3}{|l|}{ Nutritive value per $1 \mathrm{~kg}$} \\
\hline Crude protein $(\%)$ & 22.00 & 20.5 \\
\hline Metabolisable energy (MJ) & 12.5 & 13.0 \\
\hline Lysine (g) & 12.0 & 11.5 \\
\hline Methionine (g) & 5.50 & 5.20 \\
\hline Calcium (g) & 9.50 & 9.30 \\
\hline Phosphorus (g) & 4.30 & 4.10 \\
\hline
\end{tabular}

${ }^{1}$ Supplements per kg starter diet: vit. A $13500 \mathrm{IU}$; vit. $\mathrm{D}_{3} 3600 \mathrm{IU}$; vit. E $45 \mathrm{mg}$; vit. B $3.25 \mathrm{mg}$; vit B 7.5 mg; vit. $B_{6} 5 \mathrm{mg}$; vit. $B_{12} 32.5 \mathrm{mcg}$; vit. $\mathrm{K}_{3} 3 \mathrm{mg}$; biotin $150 \mathrm{mcg}$; nicotinic acid $45 \mathrm{mg}$, calcium pantothenate 15 $\mathrm{mg}$, folic acid $1.5 \mathrm{mg}$; choline chloride $447.6 \mathrm{mg}$; Mn $100 \mathrm{mg}$; Cu $1.75 \mathrm{mg}$; Fe $76.5 \mathrm{mg}$; Se $0.275 \mathrm{mg}$; I $1 \mathrm{mg}$; Zn $75 \mathrm{mg}$; Co $0.4 \mathrm{mg}$; Seldox HM (antioxidant) $25 \mathrm{mg}$; Clinacox $0.5 \% 1 \mathrm{mg}$.

${ }^{2}$ Supplements per kg grower diet: vit. A $12000 \mathrm{IU}$; vit. $\mathrm{D}_{3} 3250 \mathrm{IU}$; vit. E $40 \mathrm{mg}$; vit. $\mathrm{B}_{1} 2 \mathrm{mg}$; vit $\mathrm{B}_{2} 7.3$ mg; vit. $B_{6} 4,25 \mathrm{mg}$; vit. $B_{12} 30 \mathrm{mcg}$; vit. $K_{3} 2.25 \mathrm{mg}$; biotin $100 \mathrm{mcg}$; nicotinic acid $40 \mathrm{mg}$; calcium pantothenate $12 \mathrm{mg}$; folic acid $1.0 \mathrm{mg}$; choline chloride $335.7 \mathrm{mg}$; Mn $100 \mathrm{mg}$; Cu $1.5 \mathrm{mg}$; Fe $65 \mathrm{mg}$; Se $0.25 \mathrm{mg}$; I $0.9 \mathrm{mg}$; Zn 65 mg; Co 0.4 mg; Seldox HM (antioxidant) 25 mg; Coxidin $200100 \mathrm{mg}$.

${ }^{3}$ Supplements per kg finisher diet: vit. A $10500 \mathrm{IU}$; vit. $\mathrm{D}_{3} 2500 \mathrm{IU}$; vit. E $40 \mathrm{mg}$; vit. $\mathrm{B}_{1} 1.5 \mathrm{mg}$; vit $\mathrm{B}_{2} 5.5$ $\mathrm{mg}$; vit. $\mathrm{B}_{6} 3.25 \mathrm{mg}$; vit. $\mathrm{B}_{12} 25 \mathrm{mcg}$; vit. $\mathrm{K}_{3} 2 \mathrm{mg}$; biotin $100 \mathrm{mcg}$; nicotinic acid $35 \mathrm{mg}$; calcium pantothenate $12 \mathrm{mg}$; folic acid $1.0 \mathrm{mg}$; choline chloride $298.4 \mathrm{mg}$; Mn $80 \mathrm{mg}$; Cu 8 mg; Fe $60 \mathrm{mg}$; Se $0.2 \mathrm{mg}$; I 0.8 mg; Zn 50 mg; Co $0.4 \mathrm{mg}$; Seldox HM (antioxidant) $25 \mathrm{mg}$. 


\section{Data, sample collection and laboratory analyses}

Bird mortality was monitored throughout the study. On days 31 and 35 (during exposure to high ambient temperature) and on day 40 of the experiment (five days after exposure to heat stress), blood was collected by decapitation from 10 birds per group, the concentration of thyroid hormones $\left(\mathrm{T}_{3}\right.$ and $\left.\mathrm{T}_{4}\right)$ was determined, and blood smears were stained with a May-Grünwald Giemsa protocol. Stained leukocytes were counted under a Nikon YS 100 microscope by the differential count method. The percentage of heterophils $(\mathrm{H})$ and lymphocytes $(\mathrm{L})$ was used to calculate the H:L ratio. Thyroid hormones were determined in plasma by radioimmunoassay in an automatic gamma counter (LKB Wallace) using $\mathrm{T}_{3}\left[{ }^{125} \mathrm{I}\right]$ (REF: RK-6CT1) and $\mathrm{T}_{4}\left[{ }^{125} \mathrm{I}\right]$ (REF: RK11CT1) RIA KIT (Institute of Isotopes Co., Ltd, Budapest, Hungary).

On the same dates (days 31, 35 and 40), rectal and radiation temperature of feathered (back) and nonfeathered parts (shanks) was measured in 10 birds per group. Rectal temperature was measured with a veterinary thermometer accurate to $0.1^{\circ} \mathrm{C}$, and radiation temperature using a Cole-Parmer pyrometer. The pyrometer was placed 15 $\mathrm{cm}$ from the bird's skin.

\section{Statistical analyses}

The results were statistically analysed by one-way analysis of variance (ANOVA). The experimental unit was the individual bird. Significant differences for the means between the experimental groups were determined with Tukey's test. The effects were considered significant at a probability of $\mathrm{P}<0.05$ and $\mathrm{P}<0.01$. The statistical calculations were made using Statistica 12 software.

\section{Results}

Table 2 shows broiler mortality during rearing. Compared to the control birds, chickens from group $\mathrm{N}$ showed $0.84 \%$ and $1.67 \%$ lower mortality in the first and second rearing period, respectively. The lowest mortality during the whole rearing period was noted in group $\mathrm{N}$ compared to the other groups.

On day 35 , when the ambient temperature was $10^{\circ} \mathrm{C}$ higher than recommended, the radiation temperature of feathered parts in chickens from group $\mathrm{S}$ differed from that of birds in groups LB and $\mathrm{N}$ at $\mathrm{P}<0.01$ (Table 3). Lower radiation temperature of nonfeathered parts on day 31 was characteristic of chickens from group $\mathrm{N}$ compared to the control group $(\mathrm{P}<0.05)$. On day 35 of the study, radiation temperature of nonfeathered parts was noted in chickens from groups $\mathrm{S}$ and $\mathrm{N}$ in relation to the control birds $(\mathrm{P}<0.05)$. Broiler chickens from the experimental groups exhibited lower rectal temperature on day 31 compared to the control birds at $\mathrm{P}<0.05$ (Table 3 ).

Thyroid hormone levels in the blood of the chickens are presented in Table 4. On day 31 of the study, $\mathrm{T}_{3}$ concentration was highest in the control birds and lowest in the chickens from groups $\mathrm{LB}$ and $\mathrm{N}(\mathrm{P}<0.01)$. Differences in the $\mathrm{T}_{3}$ level were also observed on the same day between groups $\mathrm{CON}$ and $\mathrm{S}$, and between groups $\mathrm{S}$ and $\mathrm{N}(\mathrm{P}<0.05)$. The lowest $\mathrm{T}_{4}$ level was noted in the blood of broilers from group 
$\mathrm{N}$ compared to the other groups $(\mathrm{P}<0.01)$ on day 31 . The difference in $\mathrm{T}_{4}$ on that day also occurred between birds from groups LB and $\mathrm{S}(\mathrm{P}<0.05)$. On day 35 of the study, the highest $\mathrm{T}_{4}$ level was characteristic of chickens from group LB compared to those from groups $\mathrm{S}$ and $\mathrm{N}(\mathrm{P}<0.05)$. On day 40, i.e after exposure to high ambient temperature, the lowest $\mathrm{T}_{4}$ concentration was observed in broilers from group $\mathrm{N}$ compared to birds from groups $\mathrm{LB}$ and $\mathrm{S}(\mathrm{P}<0.05)$.

Table 2. Broiler mortality (\%)

\begin{tabular}{l|c|c|c|c}
\hline \multirow{2}{*}{ Days of rearing } & \multicolumn{4}{|c}{ Herbal extracts } \\
\cline { 2 - 5 } & CON & LB & S & N \\
\hline $1-21$ & 1.67 & 3.33 & 2.0 & 0.830 \\
$22-42$ & 2.50 & 1.67 & 3.00 & 0.830 \\
$1-42$ & 4.17 & 5.00 & 5.00 & 1.67 \\
\hline
\end{tabular}

$\mathrm{CON}$ - control - without herbal extract.

LB - lemon balm extract.

$\mathrm{S}$ - sage extract.

$\mathrm{N}$ - nettle extract.

Table 3. Body temperature $\left({ }^{\circ} \mathrm{C}\right)$ of broiler chickens (mean, $\mathrm{n}=10$ )

\begin{tabular}{c|c|c|c|c|c}
\hline \multirow{2}{*}{ Days of rearing } & \multicolumn{4}{|c|}{ Herbal extracts } & \multirow{2}{*}{$\begin{array}{c}\text { Pooled } \\
\text { SEM }\end{array}$} \\
\cline { 2 - 5 } & CON & LB & $\mathrm{S}$ & $\mathrm{N}$ & S \\
\hline
\end{tabular}

Radiation temperature of feathered parts

\begin{tabular}{llllll}
31 & 38.6 & 37.0 & 37.8 & 37.0 & 0.610 \\
35 & $37.7 \mathrm{AB}$ & $38.7 \mathrm{~B}$ & $36.6 \mathrm{~A}$ & $38.8 \mathrm{~B}$ & 0.450 \\
40 & 29.5 & 30.2 & 31.3 & 30.1 & 0.700 \\
\multicolumn{5}{c}{ Radiation } & temperature of unfeathered parts \\
31 & $40.3 \mathrm{a}$ & $39.7 \mathrm{ab}$ & $39.8 \mathrm{ab}$ & $39.1 \mathrm{~b}$ & 0.270 \\
35 & $40.6 \mathrm{a}$ & $40.4 \mathrm{ab}$ & $40.0 \mathrm{~b}$ & $40.1 \mathrm{~b}$ & 0.210 \\
40 & 37.1 & 37.5 & 36.4 & 36.7 & 0.660 \\
& & Rectal temperature & & \\
31 & $42.2 \mathrm{a}$ & $41.9 \mathrm{~b}$ & $41.9 \mathrm{~b}$ & $41.9 \mathrm{~b}$ & 0.080 \\
35 & 42.0 & 42.0 & 42.1 & 42.1 & 0.100 \\
40 & 41.5 & 40.6 & 41.3 & 41.3 & 0.500 \\
\hline
\end{tabular}

$\mathrm{a}, \mathrm{b}-$ values in rows with different letters differ significantly $(\mathrm{P}<0.05)$.

A, B - values in rows with different letters differ highly significantly $(\mathrm{P}<0.01)$.

Pooled SEM - Pooled standard error of mean.

$\mathrm{CON}$ - control - without herbal extract.

LB - lemon balm extract.

$\mathrm{S}$ - sage extract.

$\mathrm{N}-$ nettle extract.

On day 35, broiler chickens from group $\mathrm{N}$ showed a lower $\mathrm{H}$ :L ratio than the control group and group $\mathrm{LB}$ at $\mathrm{P}<0.01$ and $\mathrm{P}<0.05$, respectively (Table 5). 
Table 4. Plasma levels of triiodothyronine $\left(\mathrm{T}_{3}\right)$ and thyroxine $\left(\mathrm{T}_{4}\right)$ in the blood of broiler chickens (mean, $\mathrm{n}=10$ )

\begin{tabular}{|c|c|c|c|c|c|}
\hline \multirow{2}{*}{ Days of rearing } & \multicolumn{4}{|c|}{ Herbal extracts } & \multirow{2}{*}{$\begin{array}{c}\text { Pooled } \\
\text { SEM }\end{array}$} \\
\hline & $\mathrm{CON}$ & LB & S & $\mathrm{N}$ & \\
\hline \multicolumn{6}{|c|}{$\mathrm{T}_{3}(\mathrm{nmol} / \mathrm{l})$} \\
\hline 31 & $5.00 \mathrm{Aa}$ & $3.80 \mathrm{~B}$ & $4.10 \mathrm{~b}$ & $3.44 \mathrm{Ba}$ & 0.260 \\
\hline 35 & 4.80 & 4.50 & 4.30 & 3.80 & 0.280 \\
\hline 40 & 5.00 & 4.10 & 4.40 & 3.60 & 0.470 \\
\hline \multicolumn{6}{|c|}{$\mathrm{T}_{4}(\mathrm{nmol} / \mathrm{l})$} \\
\hline 31 & $56.0 \mathrm{~A}$ & $55.0 \mathrm{Aa}$ & $63.6 \mathrm{Ab}$ & $75.8 \mathrm{~B}$ & 2.80 \\
\hline 35 & $69.3 \mathrm{ab}$ & $73.8 \mathrm{a}$ & $60.3 \mathrm{~b}$ & $62.1 \mathrm{~b}$ & 3.68 \\
\hline 40 & $63.8 \mathrm{ab}$ & $72.8 \mathrm{a}$ & $72.5 \mathrm{a}$ & $59.9 \mathrm{~b}$ & 3.61 \\
\hline
\end{tabular}

$\mathrm{a}, \mathrm{b}-$ values in rows with different letters differ significantly $(\mathrm{P}<0.05)$.

A, B - values in rows with different letters differ highly significantly $(\mathrm{P}<0.01)$.

Pooled SEM - Pooled standard error of mean.

$\mathrm{CON}$ - control - without herbal extract.

LB - lemon balm extract.

$\mathrm{S}$ - sage extract.

$\mathrm{N}-$ nettle extract.

Table 5. H: $\mathrm{L}$ ratio in the blood of broiler chickens (mean, $\mathrm{n}=10$ )

\begin{tabular}{l|l|l|l|l|l}
\hline \multirow{2}{*}{ Days of rearing } & \multicolumn{5}{|c}{ Herbal extracts } \\
\cline { 2 - 6 } & $\mathrm{CON}$ & $\mathrm{LB}$ & \multicolumn{1}{c}{$\mathrm{S}$} & $\mathrm{N}$ & $\begin{array}{c}\text { Pooled } \\
\text { SEM }\end{array}$ \\
\hline 31 & 0.800 & 0.700 & 0.600 & 0.600 & 0.130 \\
35 & $1.06 \mathrm{~A}$ & $0.810 \mathrm{a}$ & $0.710 \mathrm{ABab}$ & $0.420 \mathrm{Bb}$ & 0.130 \\
40 & 0.720 & 0.510 & 0.690 & 0.510 & 0.110 \\
\hline
\end{tabular}

$\mathrm{a}, \mathrm{b}-$ values in rows with different letters differ significantly $(\mathrm{P}<0.05)$.

$\mathrm{A}, \mathrm{B}-$ values in rows with different letters differ highly significantly $(\mathrm{P}<0.01)$.

Pooled SEM - Pooled standard error of mean.

$\mathrm{CON}$ - control - without herbal extract.

LB - lemon balm extract.

$\mathrm{S}$ - sage extract.

$\mathrm{N}-$ nettle extract.

\section{Discussion}

One of the body's responses to high ambient temperature is an increase in the body's radiation temperature (Skomorucha and Sosnówka-Czajka, 2017; Cândido et al., 2020). Vasodilation increases blood flow to the skin, especially to the nonfeathered areas, which leads to increased heat dissipation from the body via radiation, convection, and conduction (Giloh et al., 2012). Exposure of poultry to high ambient temperature may also increase rectal temperature (Giloh et al., 2012; Skomorucha and Sosnówka-Czajka, 2017; Attia and Hassan, 2017; Cândido et al., 2020), which, in turn, contributes to deaths in birds unable to regulate the body temperature during heat stress (Berrong and Washburn, 1998; Attia et al., 2017 a; 
2018 a). In our study, broiler chickens from the groups supplemented with sage water extract and nettle showed lower radiation temperature of nonfeathered parts on day 31 , and on days 31 and 35 of the study, respectively, compared to the control group. The experimental groups also showed lower rectal temperature on day 31 of rearing. According to Morovat et al. (2016), supplemental antioxidants in broiler diets slow down basal metabolism and cause a considerable reduction in the body temperature. The authors noted lower rectal temperature in broiler chickens supplemented with milk thistle extract and exposed to high ambient temperature compared to the control group. Likewise, Ragab et al. (2013) found that inclusion of fennel seeds at 1 or $2 \%$ of the diet of broilers exposed to heat stress conditions caused a considerable reduction in body temperature and bird mortality. Similar results were reported by Al-Sagan et al. (2020). However, in our study, the next measurement of rectal temperature on day 5 of the exposure to high ambient temperature (day 35) showed no differences between birds supplemented with herbal extracts in drinking water and the control birds. This may indicate that the experimental herbs mitigated the negative effects of high ambient temperature on the body only during the initial period. In turn, Baghban et al. (2016) observed no changes in rectal temperature of broiler chickens exposed to heat stress $\left(32^{\circ} \mathrm{C}\right)$ for 8 hours daily in the second rearing period and receiving a diet supplemented with $0.5 \%$ turmeric or $0.5 \%$ cinnamon compared to the unsupplemented group. In our study, we found a positive effect of lemon balm and nettle on the survival of broilers during the period of supplementation (from days 22 to 42) compared to the control group.

Divi and Doerge (1996) report that flavonoids, which are strong antioxidants found in plants, inhibit thyroid peroxidase, the enzyme catalyzing biosynthesis of thyroid hormones. A decrease in plasma triiodothyronine improves the ability of birds to reduce heat production at high ambient temperatures (Yahav and McMurtry, 2001). Our results showed that during the initial period of high ambient temperature, broiler chickens supplemented with lemon balm, sage and nettle extracts in drinking water were characterised by lower blood $\mathrm{T}_{3}$ levels compared to the unsupplemented group, which was reflected in the lower rectal temperature of these birds. Similarly, El-Shoukary et al. (2014) obtained a lower blood $\mathrm{T}_{3}$ level in chickens supplemented with $1 \%$ black cumin seeds or $2 \%$ coriander seeds and exposed to heat stress $\left(34^{\circ} \mathrm{C}\right)$ from 14 to 42 days of rearing. Another study showed $\mathrm{T}_{3}$ concentration to increase in the blood of broiler chickens exposed to heat stress and fed a diet supplemented with natural antioxidants (Hassan et al., 2016; Wan et al., 2017; Sadeghi and Moghaddam, 2018). Sadeghi and Moghaddam (2018) found that dietary inclusion of ginger or garlic powder at $0.5 \%$ increased $\mathrm{T}_{4}$ concentration in the blood of broiler chickens exposed to high ambient temperatures. The authors observed no effect of supplementing cinnamon powder at $0.5 \%$ on the blood level of this hormone in the experimental birds. In addition, El-Shoukary et al. (2014) and Wan et al. (2017) found no changes in $\mathrm{T}_{4}$ concentration in the blood of chickens exposed to high ambient temperatures and supplemented with herbs. In our study, we observed $\mathrm{T}_{4}$ blood concentration to increase in broiler chickens supplemented with nettle extract in drinking water on the second day of thermal challenge. In further studies, the inclusion of herbal extracts in drinking water did not have any effect on the $\mathrm{T}_{4}$ blood level of the birds. 
Heat stress contributes to lower lymphocyte production and higher heterophil production in the avian blood, which increases the H:L ratio (Vermette et al., 2017; Attia and Hassan, 2017; Attia et al., 2017 a; 2018 a; Xu et al., 2018) Therefore, the $\mathrm{H}: \mathrm{L}$ ratio is used as a reliable indicator of stress in birds (Vermette et al., 2017; Attia et al., 2017 c). Najafi and Torki (2010) observed that a diet with $200 \mathrm{mg}^{-} \mathrm{kg}^{-1}$ of essential oils from thyme and cinnamon caused a significant decrease in heterophils and an increase in blood lymphocytes of birds compared to the group fed the diet without herbal extracts. In addition, Attia et al. (2017 b; 2018 b) observed similar results. In turn, Khafar et al. (2019) showed that a diet supplemented with essential oil from thyme at 150 and $200 \mathrm{mg}^{\cdot} \mathrm{kg}^{-1}$ may effectively protect chickens from the negative effects of heat stress, among others by reducing the $\mathrm{H}: \mathrm{L}$ ratio. Hassan et al. (2016) noted a reduction in the H:L ratio in the blood of broiler chickens exposed to high ambient temperature and receiving a diet with Moringa oleifera at $0.1,0.2$ and $0.3 \%$. A reduction in the $\mathrm{H}: \mathrm{L}$ ratio in the blood of chickens exposed to heat stress was also obtained by Hosseini et al. (2016) after dietary inclusion of essential oil from turmeric at $400 \mathrm{mg}^{-1} \mathrm{~kg}^{-1}$. In our study, the decreased $\mathrm{H}: \mathrm{L}$ ratio in relation to the control group was obtained for birds supplemented with $2 \mathrm{ml} / 1$ nettle extract in drinking water.

In summing up, the extracts from lemon balm, sage and nettle added to drinking water at $2 \mathrm{ml} / \mathrm{l}$ caused, during the initial period of heat stress, a decrease in the blood level of thyroid hormone (triiodothyronine) and in rectal temperature of the experimental broiler chickens. This suggests that dietary inclusion of extracts from the studied herbs may alleviate the negative effects of short-term heat stress. Broilers receiving the nettle extract were also characterised by lower radiation temperature of featherless parts and a lower H:L ratio in the blood during the period of increasing ambient temperature, as well as by the lowest mortality percentage. It can therefore be concluded that dietary inclusion of nettle in the form and concentration used in our study had the most beneficial effect on the physiological status (body temperature, level of thyroid hormones and H:L ratio) of broiler chickens exposed to elevated ambient temperatures $\left(30^{\circ} \mathrm{C}\right)$, and thus on their welfare.

\section{References}

Abd E1-Hack M.E., Abdelnour S.A., Taha A.E. Khafaga A.F. Arif M., Ayas an T., Swelum A.A., Abukhalil M.H., Alkahtani S., Aleya L., Abdel-Daim M.M. (2020). Herbs as thermoregulatory agents in poultry: An overview. Sci. Total Environ., 703: 134399.

A 1 - S a gan A.A., Khalil S., Hus s e in E.O., A t ti a Y.A. (2020). Effects of fennel seed powder supplementation on growth performance, carcass characteristics, meat quality, and economic efficiency of broilers under thermoneutral and chronic heat stress conditions. Animals, 10: 206.

A t t i a Y.A., A 1 - H a r th i M.A. (2015). Nigella seed oil as an alternative to antibiotic growth promoters for broiler chickens. Eur. Poultry Sci., 79, DOI: 10.1399/eps.2015.80

A t ti a Y.A., Has s an R.A. (2017). Broiler tolerance to heat stress at various dietary protein/energy levels. Eur. Poultry Sci., 81, DOI: 10.1399/eps.2017.171

A t t i a Y.A., Has s a n R.A., Tag E 1 - D in A.E., A b o u-S h e h e ma B.M. (2011). Effect of ascorbic acid or increasing metabolizable energy level with or without supplementation of some essential 
amino acid on productive and physiological traits of slow-growing chicks exposed to chronic heat stress. J. Anim. Physiol. Anim. Nutr., 95: 744-755.

A t t i a Y.A., A 1 - H a r th i M.A., E 1 - S h a fe y A.S., R e h a b Y.A., K i m W.K. (2017 a). Enhancing tolerance of broiler chickens to heat stress by supplementation with vitamin $\mathrm{E}$, vitamin $\mathrm{C}$ and/or probiotics. Ann. Anim. Sci., 17: 1-15.

A t t i a Y.A., A l- Harth i M.A., H a s s a n S.S. (2017 b). Turmeric (Curcuma longa Linn.) as a phytogenic growth promoter alternative for antibiotic and comparable to mannan oligosaccharides for broiler chicks. Rev. Mex. Cienc. Pecu., 8: 11-21.

A t t i a Y.A., B a k h a s h w a in A.A., B e r t u N.K. (2017 c). Thyme oil (Thymus vulgaris L.) as a natural growth promoter for broiler chickens reared under hot climate. Ital. J. Anim. Sci., 16: 275-282.

A t t i a Y.A., B a kh a s h w a in A.A., B e r t u N.K. (2018 a). Utilisation of thyme powder (Thyme vulgaris L.) as a growth promoter alternative to antibiotics for broiler chickens raised in a hot climate. Eur. Poultry. Sci., 82, DOI: 10.1399/eps.2018.238.

A t t i a Y.A., A 1 - H a r th i M.A., E 1 n a g g a r A.S. (2018 b). Productive, physiological and immunological responses of two broiler strains fed different dietary regimens and exposed to heat stress. Ital. J. Anim. Sci., 17: 686-697.

B a ghban P., Dan e shy ar M., N ajafi R. (2016). Effects of cinnamon (Cinnamomum zeylanicum) and turmeric (Curcuma longa) powders on performance, enzyme activity, and blood parameters of broiler chickens under heat stress. Poultry Sci. J., 4: 47-53.

B errong S.L., Wa sh burn K.W. (1998). Effect of genetic variation on total plasma protein, body weight gains, and body temperature responses to heat stress. Poultry Sci., 77: 379-385.

B onetti G., Tedeschi P., Meca G., Bertelli D., Mañes J., B a randolin i V., Mai et ti A. (2016). In vitro bioaccessibility, transepithelial transport and antioxidant activity of Urtica dioica L. phenolic compounds in nettle based food products. Food Funct., 7: 4222-4230.

C ân d i do M.G.L., T i n ô c o I.F.F.,A 1 b i no L.F.T., F r e it a s L.C.S.R., S a n to s T.C., C e c on P.R., G a t e s R.S. (2020). Effects of heat stress on pullet cloacal and body temperature. Poultry Sci., doi. org/10.1016/j.psj.2019.11.062

Cheng Y.F., Chen Y.P., Chen R., Su Y., Zhang R.Q., He Q.F., Wang K., Wen C., Z h o u Y.M. (2019). Dietary mannan oligosaccharide ameliorates cyclic heat stress-induced damages on intestinal oxidative status and barrier integrity of broilers. Poultry Sci., 98: 4767-4776.

D i v i R.L., D o e r g e D.R. (1996). Inhibition of thyroid peroxidase by dietary flavonoids. Chem. Res. Toxicol., 49: 2495-2502.

E 1 - S h o u kary R.D.M., D a rw is h M.H.A., A b d e 1 - R a h m a n M.A.M. (2014). Behavioral, performance, carcass traits and hormonal changes of heat stressed broilers feeding Black and Coriander Seeds. J. Adv. Vet. Res., 4: 93-101.

Giloh M., Shinder D., Yahav S. (2012). Skin surface temperature of broiler chickens is correlated to body core temperature and is indicative of their thermoregulatory status. Poultry Sci., 91 : $175-188$.

Has s a H.M.A., E1-Moniary M.M., Hamouda Y., E1-Daly E.F., Amani W.Y., Abd E 1 - A z e e m N.A. (2016). Effect of different levels of Moringa oleifera leaves meal on productive performance, carcass characteristics and some blood parameters of broiler chicks reared under heat stress conditions. Asian J. Anim. Vet. Adv., 11: 60-66.

Hosseini S.M., Nazarizadeh H., Ahani S., Azghandi M.V. (2016). Effects of mannan oligosaccharide and Curcuma xanthorrhiza essential oil on the intestinal morphology and stress indicators of broilers subjected to cyclic heat stress. Arch. Anim. Breed., 59: 285-291.

Ji ang S., Moh a m med A.A., J a c ob s J.A., C r a mer T.A., Ch eng H.W. (2020). Effect of synbiotics on thyroid hormones, intestinal histomorphology, and heat shock protein 70 expression in broiler chickens reared under cyclic heat stress. Poultry Sci., 99: 142-150.

Kasapidou E., Giannenas I., Mitlianga P., Sinapis E., Bouloumpasi E., Petroto s K., Man ouras A., K y riazak is I. (2014). Effect of Melissa officinalis supplementation on growth performance and meat quality characteristics in organically produced broilers. Brit. Poultry Sci., 55: 774-784.

Khafar K.R., Mojtahedin, A., Rast egar N., Neytali K.M., Olfati A. (2019). Dietary inclusion of thyme essential oil alleviative effects of heat stress on growth performance and immune system of broiler chicks. Iran. J. Appl. Anim. Sci., 9: 509-517. 
K u m a r S., P a n g en i D., Yang X., P a rk S.O. (2017). Effect of ascorbic acid in the drinking water and betaine in the diet on performance, blood haematology, IgG and HSP 70 gene expression in Pekin ducks (Anas platyrhynchos domesticus) reared under high temperatures. Eur. Poultry Sci., 81, DOI: $10.1399 /$ eps.2017.177

L a r a L.J., R o s t a g n o M.H. (2013). Impact of heat stress on poultry production. Animals, 3: 356369.

Mack L.A., F e lve r-Gant J.N., D e nn is R.L., C heng H.W. (2013). Genetic variations alter production and behavioral responses following heat stress in 2 strains of laying hens. Poultry Sci., 92: 285-294.

Morovat M., Chamani M., Zarei A., S a deghi A.A. (2016). Dietary but not in ovo feeding of Silybum marianum extract resulted in an improvement in performance, immunity and carcass characteristics and decreased the adverse effects of high temperatures in broilers. Brit. Poultry Sci., 57: 105-113.

Najafi P., Torki M. (2010). Performance, blood metabolites and immunocompetence of broiler chicks fed diets included essential oils of medicinal herbs. J. Anim. Vet. Adv., 9: 1164-1168.

Olanrewaju H.A., Purswell J.L., Collier S.D., Branton S.L. (2010). Effect of ambient temperature and light intensity on physiological reactions of heavy broiler chickens. Poultry Sci., 89: 2668-2677.

P ouli os E., G i a g in is C., Va s i o s G.K. (2020). Current state of the art on the antioxidant activity of sage (Salvia spp.) and its bioactive components. Planta Med., 86: 224-238.

R a ga b M.S., N a m ra M.M.M., A ly M.M.M., F a thi M.A. (2013). Impact of inclusion fennel seeds and thyme dried leaves in broiler diets on some productive and physiological performance during summer season. Egypt. Poultry Sci., 33: 197-219.

R e h m a n Z., Ch and N., K h a n R.U., N a z S., A 1 h i d a r y I.A. (2018). Serum biochemical profile of two broiler strains supplemented with vitamin E, raw ginger (Zingiber officinale) and Learnitine under high ambient temperatures. S. Afr. J. Anim. Sci., 48: 935-942.

S a d e ghi A.A., Moghaddam M. (2018). The effects of turmeric, cinnamon, ginger and garlic powder nutrition on antioxidant enzymes status and hormones involved in energy metabolism of broilers during heat stress. Iran. J. Appl. Anim. Sci., 8: 125-130.

Saeed M., Abbas G., Alagawany M., Kamboh A.A., Abd El-Hack M.E., Khafag a A.F., Ch a o S. (2019). Heat stress management in poultry farms: A comprehensive overview. J. Therm. Biol., 84: 414-425.

S k o morucha I., S os nówka-Czajka E. (2013): Effect of water supplementation with herbal extracts on broiler chicken welfare. Ann. Anim. Sci., 13: 849-857.

S k o morucha I., S os nów k a - C z a j k a E. (2017). Physiological parameters in broiler chickens reared under different housing systems during a period of high temperatures. Acta Sci. Pol. Zoot., 16: 25-34.

Sohail M.U., Ijaz A., Yous af M.S., Ashraf K., Zaneb H., Aleem M., Rehman H. (2010). Alleviation of cyclic heat stress in broilers by dietary supplementation of mannan-oligosaccharide and Lactobacillus-based probiotic: Dynamics of cortisol, thyroid hormones, cholesterol, C-reactive protein, and humoral immunity. Poultry Sci., 89: 1934-1938.

Song Z.H., Cheng K., Zheng X.C., Ahmad H., Zhang L.L., Wang T. (2018). Effects of dietary supplementation with enzymatically treated Artemisia annua on growth performance, intestinal morphology, digestive enzyme activities, immunity, and antioxidant capacity of heat-stressed broilers. Poultry Sci., 97: 430-437.

Vermette C.J., Henrikson Z.A., Schwean-Lardner K.V., Crowe T.G. (2017). Influence of hot exposure on 12-week-old turkey hen physiology, welfare, and meat quality and 16-week-old turkey tom core body temperature when crated at transport density. Poultry Sci., 96: 3836-3843.

Wan X., Jiang L., Zhong H., Lu Y., Zhang L., Wang T. (2017). Effects of enzymatically treated Artemisia annua L. on growth performance and some blood parameters of broilers exposed to heat stress. Anim. Sci. J., DOI: 10.1111/asj.12766

Wang Y., Saelao P., Chanthavixay K., Gallardo R., Bunn D., Lamont S.J., Dekkers J.M., Kelly T., Z hou H. (2018). Physiological responses to heat stress in two genetically distinct chicken inbred lines. Poultry Sci., 97: 770-780. 
Wang Y., Xia L., Guo T., Heng C., Jiang L., Wang D., Wang J., Li K., Zhan X. (2020). Research Note: Metabolic changes and physiological responses of broilers in the final stage of growth exposed to different environmental temperatures. Poultry Sci., 99: 2017-2025.

X u Y., L a i X., L i Z., Z h a n g X., L u o Q. (2018). Effect of chronic heat stress on some physiological and immunological parameters in different breed of broilers. Poultry Sci., 97: 4073-4082.

Yahav S., McMurtry J.P. (2001). Thermotolerance acquisition in broiler chickens by temperature conditioning early in life - the effect of timing and ambient temperature. Poultry Sci., 80: $1662-1666$.

Received: 4 XI 2020

Accepted: 17 II 2021 